Document downloaded from:

http://hdl.handle.net/10251/136498

This paper must be cited as:

Andruskiewicz, P.; Najt, P.; Durrett, R.; Biesboer, S.; Schaedler, T.; Payri, R. (2018). Analysis of the effects of wall temperature swing on reciprocating internal combustion engine processes. International Journal of Engine Research. 19(4):461-473. https://doi.org/10.1177/1468087417717903

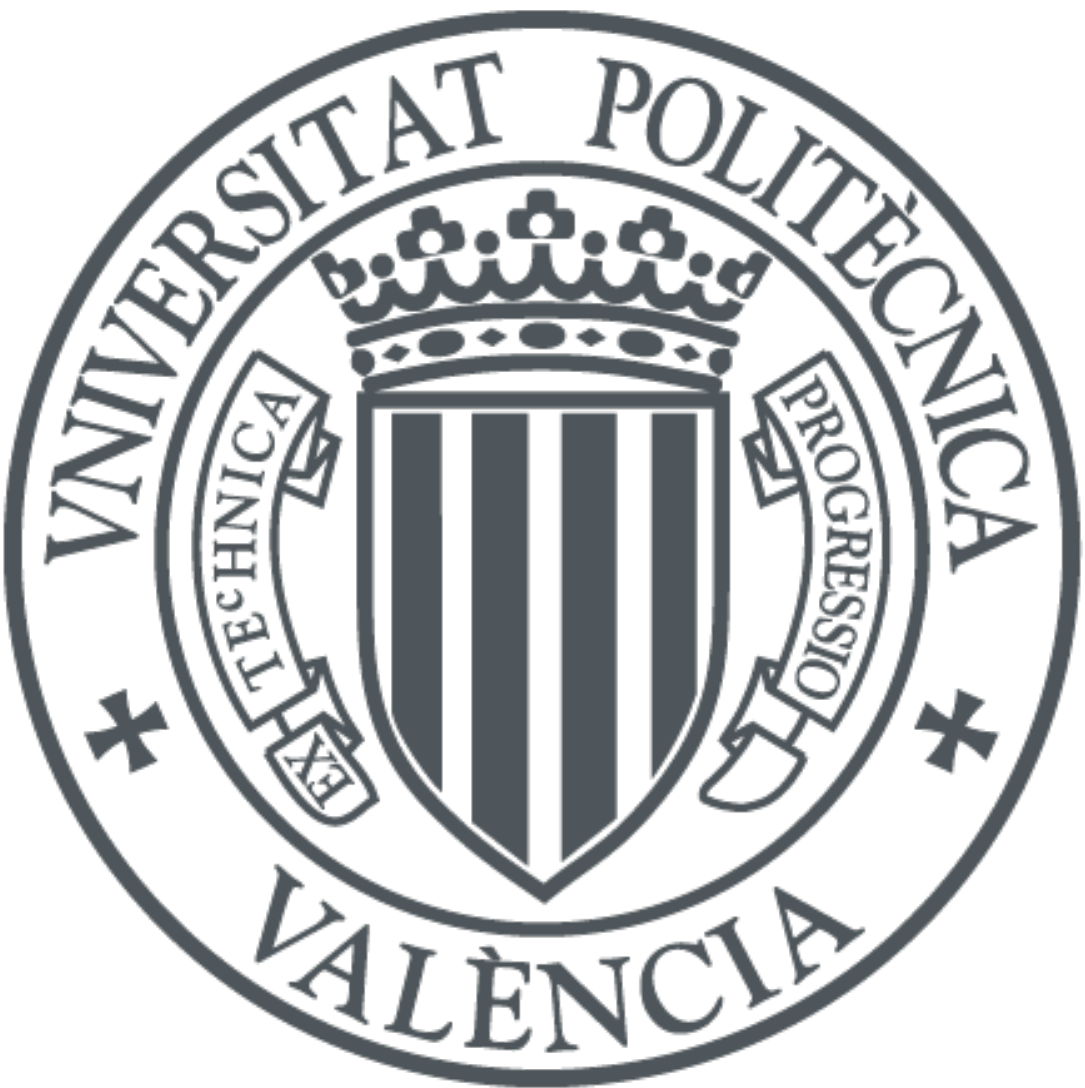

The final publication is available at

https://doi.org/10.1177/1468087417717903

Copyright SAGE Publications

Additional Information 


\title{
Analysis of the Effects of Wall Temperature Swing on Reciprocating Internal Combustion Engine Processes
}

\author{
Peter Andruskiewicz, Paul Najt, Russell Durrett - General Motors \\ R\&D, PSR Lab
}

Scott Biesboer, Tobias Schaedler - HRL Laboratories

\begin{abstract}
Raul Payri - Universitat Politecnica de Valencia, CMT Motores Termicos
\end{abstract}

\begin{abstract}
A thermal wall temperature-swing (TWTS) model was built to capture the transient effects of various material properties and coating layers on the intra-cycle wall temperature of an internal combustion engine. This model was used with a thermodynamic engine simulation to predict and analyze the effects of different types of in-cylinder insulation on engine performance. Coatings that allow the surface temperature to swing in response to the gas' cyclical heat flux enable approximately $1 / 3$ of the energy that was prevented from leaving the gas during expansion to be recovered while improving volumetric efficiency (VE). Reductions in compression work due to better VE and less heat transfer from the walls to the gas accounted for half of the improvements, while additional work extraction during combustion and expansion accounted for the other half. As load increases, the temperature swing and benefits derived from it also increase. NSFC improvements of 0.5 to $1 \%$ were seen with a highly swinging coating in the throttled regime for a realistic engine geometry and coating area, up to $2.5 \%$ at high loads.
\end{abstract}

\section{Introduction}

Increasing emissions and fuel consumption standards across the world are driving engine and vehicle manufacturers to improve overall vehicle efficiency and environmental impact as much as possible, while the competitive nature of the market ensures that solutions must be very cost-effective. Two of the megatrends in engine design to address these constraints are the moves to downsize and to downspeed light-duty engines, effectively spinning a smaller engine more slowly at a higher specific load to minimize pumping and frictional losses in everyday usage. The limits to these trends are generally related to high in-cylinder temperatures and pressures, low-load torque capacity dictated by the boosting device used, engine knock and fuel enrichment in gasoline engines, and increased emissions and high-speed load potential for diesel engines. In this environment, in-cylinder thermal management could prove to be a very important tool for further improving the efficiency and environmental friendliness of the internal combustion engine. 
Over the range of speeds and loads encountered in passenger vehicle use, approximately $30 \%$ of the fuel energy leaves the cylinder through heat transfer to the combustion chamber walls, and another 5-10\% through the exhaust port walls. This energy is transferred to the coolant at a relatively low temperature, and thus has low availability for reclamation. Preventing this energy loss from the hot combustion gasses could increase the useful crank work that the gas performs directly, as well as to improve the function of devices such as turbochargers, exhaust compounding, and aftertreatment catalysts that rely on exhaust energy to function. The need for engine cooling drives further vehiclelevel losses such as larger coolant pumps, higher coolant pressures and flows, and larger heat exchangers with greater aerodynamic drag. Additionally, thermal barriers act as component thermal protection to enable greater specific output, aiding further downsizing and downspeeding. There has been considerable recent activity to minimize heat losses and improve engine performance through in-cylinder insulation (1) (2) (3) (4) (5)

In-cylinder insulation has been investigated in earnest beginning with the efforts of Cummins and TACOM to improve military diesel engine performance, smoke levels, flexible fuel capability, and to reduce cooling requirements (6). Many of the early attempts used monolithic ceramics (7) (8) such as silicon carbide (9), partially-stabilized zirconia (10), and silicon nitride (11), as well as the removal of coolant (12) and plasmasprayed zirconia (13). A significant reduction in heat transfer was reported by most of these sources, but any improvements in brake output required an energy recovery device in the exhaust such as a turbocharger or turbine compounding system. Naturally aspirated results generally showed no benefit to piston work; all of the energy redirected by the insulation appeared in the exhaust. Volumetric efficiency (VE) was negatively impacted by between $3-10 \%$ depending on the level of insulation, forcing lower load or richer incylinder conditions. Turbochargers could recover some of the excess energy in the exhaust to overcome the VE penalty and to provide a benefit in brake work, but that benefit was derived mostly from the pumping loop. Turbocompounding continued this trend further, allowing the recovery of more work at high loads back to the crankshaft.

Some authors (7) (11) reported an increase in heat transfer with increased insulation during combustion and expansion, if not overall. The proposed hypothesis for this behavior was that the thermal boundary layer had shrunk with hotter walls, which allowed hotter gas closer where it could lose more heat. Other explanations were offered, such as increases in surface roughness, permeability, and changes in in-cylinder flow that increased the heat transfer coefficient or area sufficiently to overcome the insulation.

It was recognized relatively early that simply increasing the wall temperature to achieve zero net heat transfer would not result in significant engine performance gains due to the reduction in volumetric efficiency and increase in compression work. Wallace et. al. (14) analytically investigated the difference between isothermal wall temperature and instantaneously adiabatic conditions, and discovered a large difference in indicated efficiency and air delivery ratio between these cases. Modeling studies deriving from this analysis (15) highlighted the benefits of an insulating wall of sufficiently low heat capacity such that its surface temperature tracked the gas temperature throughout the cycle, approximating the adiabatic case. This enabled large reductions in the peak heat 
transfer rate while allowing the wall temperature to fall with the gas temperature during the intake and compression strokes to avoid detrimentally affecting VE. Work required for compression was reduced, enabling a brake benefit even with naturally aspirated engines. Further experimental studies with air-gap-insulation (16) showed that the presence of metal mass over the air gap negated the temperature swing properties of the air gap, and emphasized the importance of the properties of the wall surface. Other researchers confirmed the same basic findings, emphasizing the importance of wall temperature swing in insulation performance (17) (18) (19) (20).

The amount of surface temperature swing is dictated by the bulk material properties of the material in contact with the gas. Figure 1 depicts lines representing the surface temperature swing predicted by Kosaka et. al. (1) in more recent studies. The surface temperature swing is dependent on the material properties, but is also a strong function of engine operating parameters such as load, combustion phasing, engine speed, and any others that affect the gas temperature, heat transfer coefficient, and time for heat transfer. Reductions in either the volumetric heat capacity or the thermal conductivity will result in greater levels of temperature swing.
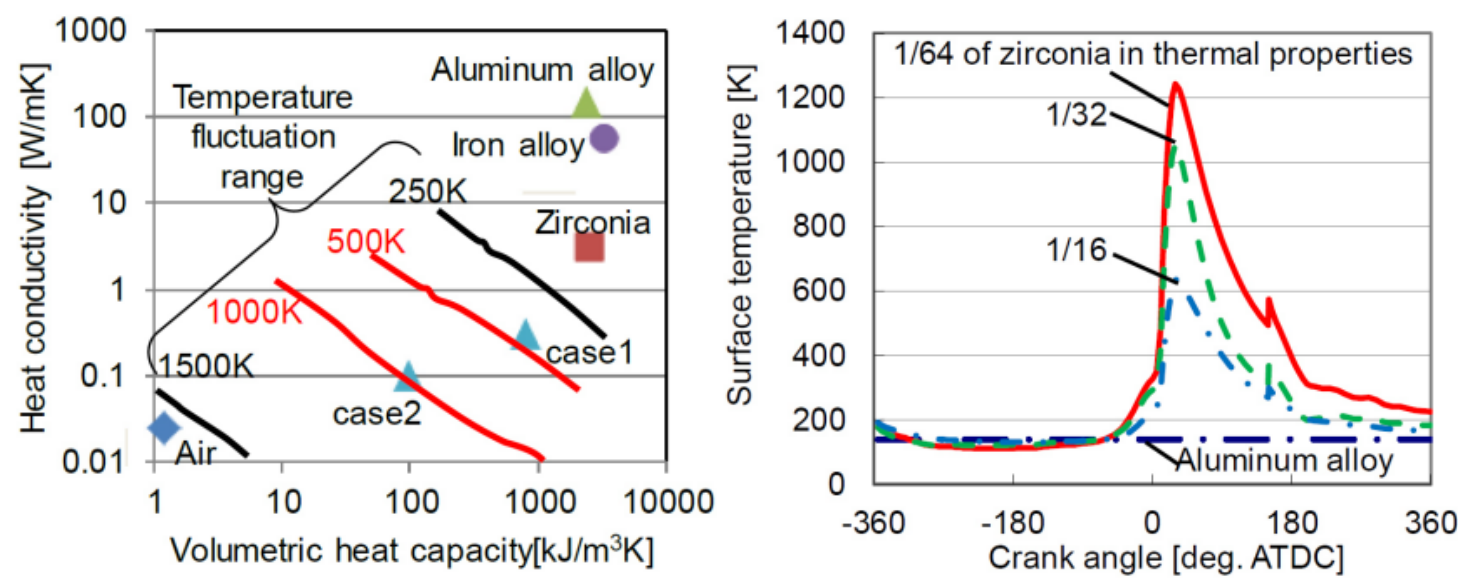

Figure 1: Material Properties and Temperature Swings from Reference (1)

$$
\Delta T \sim \frac{1}{\sqrt{\rho \times c \times k}}
$$

Equation 1

In general, the surface temperature swing will be related to the material properties through the relation proposed by Assanis (19) in Equation 1. The volumetric heat capacity " $\rho \times c$ " of a bulk material is a function of the composition (mass heat capacity " $c$ "), and of the density of the bulk material " $\rho$ ". The effective thermal conductivity " $k$ " is dependent on the material structure, types of elemental bonds, and larger-scale geometric features such as the effective cross-section perpendicular to conduction and path length in the direction of conduction. A reduction in bulk density through the introduction of voids in the solid material will both directly affect the volumetric heat capacity as well as the conductivity by decreasing the cross-section of solid material. Since air has a volumetric heat capacity of approximately $1 / 1000^{\text {th }}$ and a thermal conductivity of $1 / 100^{\text {th }}$ of any of the solid materials shown, the addition of air into a bulk material through porosity can greatly improve the thermal properties necessary for temperature swing. Porosity 
International Journal of Engine Research https://doi.org/10.1177/1468087417718115 introduced by spray application of ceramics such as plasma-sprayed zirconia, or engineered into the structure like SiRPa (3) can have a much larger impact on both the thermal conductivity and heat capacity due the void volume. This approach has been measured to demonstrate much larger temperature swings than conventional materials, resulting in gains in brake work (2).

\section{Thermodynamic Engine Modeling Methodology}

A 0-dimensional commercially available engine thermodynamic model was used to simulate a single-cylinder spark-ignited (SI) experimental engine, with geometry shown in Table 1. Thermodynamic model predictions including all sub-models were calibrated to experimental data. Three combinations of speed and fueling rate were investigated; 2000 RPM and $60 \mathrm{mg} / \mathrm{cycle}$ (High-Load), $2000 \mathrm{RPM}$ and $20 \mathrm{mg} / \mathrm{cycle}$ (Mid-Load), and 1000 RPM and $20 \mathrm{mg} / \mathrm{cycle}$ (Low-Speed), with most analysis at High Load. These three points are shown in Figure 2 with a conventional wall temperature boundary.

Table 1: Engine Geometry

\begin{tabular}{|r|c|}
\hline Bore & $86 \mathrm{~mm}$ \\
\hline Stroke & $94.6 \mathrm{~mm}$ \\
\hline Comp. Ratio & 10.6 \\
\hline Combustion Type & $\mathrm{SI}$ \\
\hline Chamber Type & 4-valve, Pent-roof \\
\hline Intake Duration & $260^{\circ}$ \\
\hline Exhaust Duration & $230^{\circ}$ \\
\hline
\end{tabular}

The combustion chamber itself models the gas as burned and unburned zones, with mass moving from unburned to burned zones as prescribed by the heat release curve. Gas properties are solved for based on the concentrations of basic molecules such as $\mathrm{N}_{2}, \mathrm{O}_{2}$, $\mathrm{CO}_{2}, \mathrm{CO}, \mathrm{H}_{2} \mathrm{O}, \mathrm{H}_{2}$, and Fuel. Concentrations of these molecules in the gas and fuel sources are specified, with perfect mixing assumed within sub-volumes and the cylinder itself. Gaseous mixture concentrations in-cylinder are solved for during combustion by solving equilibrium reactions to achieve the prescribed heat release rate.

Intake and exhaust flow was modeled as a series of sealed pipes and volumes to capture wave dynamics in the manifolds and ports. The geometry of the model was made to match the physical engine as closely as possible up until large settling tanks for the intake and exhaust systems to capture wave dynamics. These tanks were modeled as endenvironments at constant pressure and temperature that effectively acted as sources and sinks for the gas. Modeling was done on a mass-flow-basis such that a fixed fuel mass was injected and the intake pressure was adjusted to achieve a constant air-fuel ratio of 14.2, resulting in constant air mass flow. The exhaust pressure was set at the maximum of $104 \mathrm{kPa}$ or the intake pressure plus $10 \mathrm{kPa}$ to simulate turbocharged boundary conditions while avoiding the more complex interplay between the turbomachine efficiencies, exhaust temperature, and engine volumetric efficiency, thereby simplifying the analysis and focusing on the in-cylinder effects. 

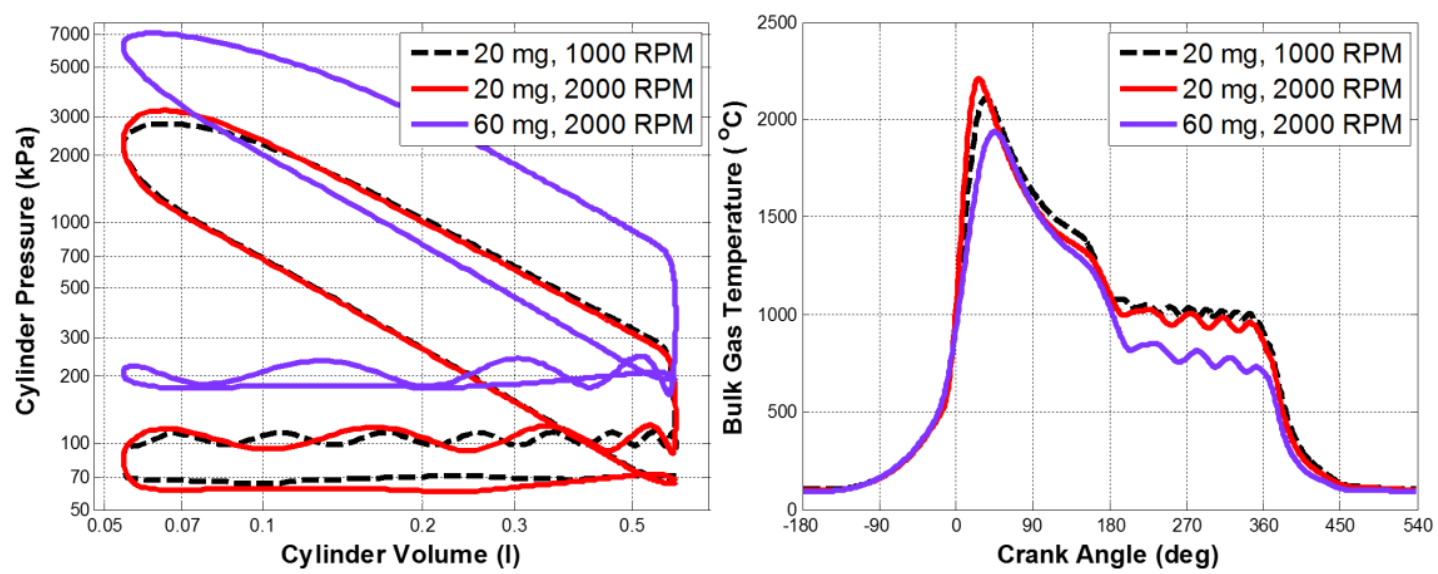

Figure 2: Cylinder Pressure and Bulk Gas Temperature for Three Operating Points

Combustion was modeled as a simple Wiebe function with CA50 fixed at $18^{\circ}$ aTDC for the high load point, at $8^{\circ}$ for the mid-load point, and at $12^{\circ}$ for the low-speed point. The burn duration was held fixed at each point, specified as a function of the CA50. Heat transfer was modelled using a continuous form of the Woschni equations (21), driven by the need to avoid discontinuous steps in heat transfer rate that would produce unrealistic effects in the wall temperatures. The bulk gas temperature was used in heat transfer calculations. A global multiplier on the heat transfer coefficient was applied for each operating point based on the fueling rate and combustion phasing, to correct the overall Woschni predictions to measured data taken with a stoichiometric boosted SI engine. This global multiplier was held fixed for each speed \& fueling point.

\section{Thermal Structure Modeling Methodology}

A 2-dimensional implicit finite-element Thermal Wall Temperature Swing (TWTS) model was written to interface with the engine thermodynamic model and the experimental data analysis. The purpose of this model was to be able to predict the instantaneous surface temperatures of the engine components based on the material properties, component structure, engine operating conditions, and boundary conditions. Implicit (backwards-difference) methods were used to ensure model stability while maintaining freedom of timestep lengths and node spacing. The engine was assumed to be radially symmetric, neglecting details such as the piston wrist-pin structure, possible siamesed-bore details, and specific valve positioning in the head. This level of simplification was deemed acceptable since the combustion chamber temperature and heat transfer model in the data analysis and thermodynamic simulation were fundamentally zero-dimensional, and the resulting surface temperatures were being used to predict bulk heat transfer trends. Similarly, maximum precision was desired at the wall's combustion surface where heat transfer is primarily 1-dimensional away from the gas, so geometric details perpendicular to this dimension were simplified to minimize complexity and speed solution of the model.

Single-zone bulk combustion gas temperature and heat transfer coefficient as predicted by a convection model using Woschni's (21) formulation described previously were 
taken as the thermal source. Using the individual burned and unburned zone temperatures and separate convection coefficients could add further resolution, but the difficulties in calibrating and consistently tracking and predicting flame-wetted areas between the thermodynamic model and experimental data, as well as the additional resolution necessary in the thermal model, would have added substantial complexity and analysis time without commensurate improvements in fundamental understanding of the results. The temperatures and heat transfer coefficients to thermal sinks for each component were calibrated based on experimental data and values in literature. Temperature-dependent material properties were taken from literature or experimentally measured, and linearly interpolated for each node at each timestep throughout the engine cycle.

The output of the TWTS model was validated against results from a commercially available thermal finite element software package. The validation cases consisted of 1dimensional heat transfer through 2 and 3-layer components while varying the layer thicknesses and material properties. The cylinder temperature and heat transfer coefficient were generated by the thermodynamic model at a high-load condition. Agreement between the reference software and TWTS is very good, and all of the general trends and magnitudes are well-captured by the TWTS model.

\section{TWTS Model Calibration with Experimental Data}

Once the general model formulation was validated, the results were calibrated to experimental data. A more detailed model with two-dimensional piston, cylinder liner, head, intake and exhaust valve elements was constructed. Heat could be passed between components through convection coefficients. Valve and piston positions were tracked and incorporated into the thermal connections. Heat transfer coefficients between components and to temperature sinks were the only parameters varied to get agreement with data. Heat transfer coefficients between the combustion gas and component surfaces were dictated by thermodynamic analysis, while component geometries and material properties were fixed.
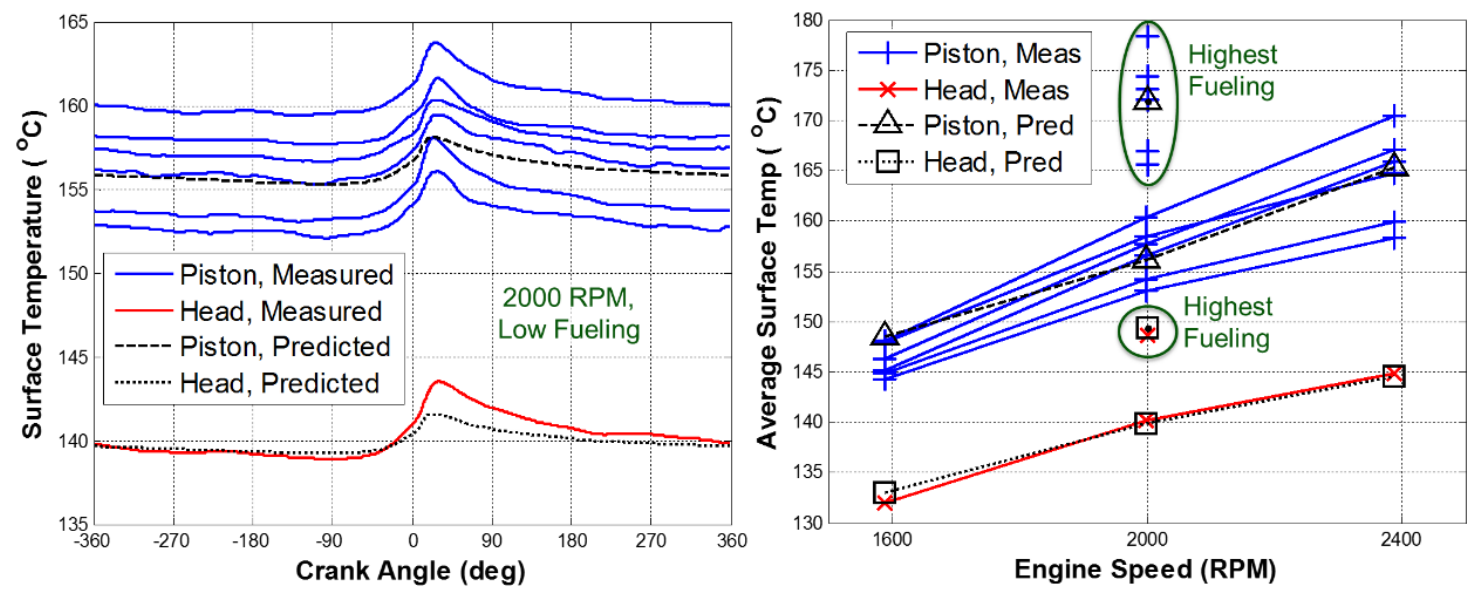

Figure 3: Piston (Multiple Locations) and Head Measurements vs Model Predictions

Piston and head surface temperatures throughout the cycle could be compared to experimental data taken by Guralp et. al. (22). The original measurements of multiple 
piston and a single head location were obtained for four data points and were processed using the same experimental data analysis routines used to calibrate the thermodynamic model for consistency. Woschni's heat transfer correlation was modified according to the method described in (23) to ensure applicability to homogeneous charge compression ignition (HCCI). Surface temperatures at multiple points on the piston surface were measured using a fast-response heat flux probe in reference (22). This probe is essentially a very low mass thermocouple fixed to the combustion chamber surface which can accurately capture the wall temperature variations throughout the cycle. The engine itself was very similar to the engine modeled by this research, with the same bore, stroke, family of pistons, and lack of an under-crown oil-jet for piston cooling. The experimental piston surface had many facets designed to enable the HCCI combustion system, including a central bowl region with a thinner cross-section and a higher outside top-land area with a thicker cross-section. Three of the heat flux probes were located within the bowl, and two were on the top-land. Output from these heat flux probes is shown in the left plot in Figure 3 for one of the four experimental points. The right plot shows the cycle-averaged temperature of the five piston surface thermocouples and the head surface thermocouple at all four points, as well as the model's predictions.

As can be seen, the model captures the average temperature for the head and piston well at all data points. Notably, the inter-cycle wall temperature swing predicted by the model is approximately half of individual measured values. The primary cause of this is spatial averaging; modeled results only comprehend the average gas temperature and convection coefficient calculated from temperature, and will not see the sudden spike that a physical probe mounted in the engine will experience as local fuel-air mixture combusts. Modifications to Woschni's convection coefficient as described previously for HCCI combustion will reduce the predicted heat flux spike by removing the pressure amplification term representing the flame front. However, because even HCCI combustion occurs over a finite period of time and space due to thermal gradients incylinder, local measurements of wall temperature should be expected to see greater transient heat flux peaks than the area-averaged global heat transfer coefficient would predict. Comparing the predicted piston temperature swing to the average of the five piston measurements reveals that the difference in temperature swing for this average component decreases the error by more than half when comparing to the individual measurements available.

Comparable experimental measurements of the intake and exhaust valve temperatures were found in the work by Yang et. al. (24). The intake and exhaust valves in a 2.0 liter 4-cylinder naturally aspirated SI engine were instrumented with thermocouples in the center of the valve face and along the valve backside. The engine geometry in this reference was very similar to the single-cylinder engine used as the basis of the TWTS model. Temperatures were measured at full load at 3600 and 5400 RPM. Other engine data provided in the reference was used to help extrapolate experimental single cylinder results taken at similar full load points to provide comparable boundary conditions to those in the reference. Convection between the valve stem and valve guide and between the valve edge and valve seat were calculated using the coefficients measured by Wisniewski (25). 


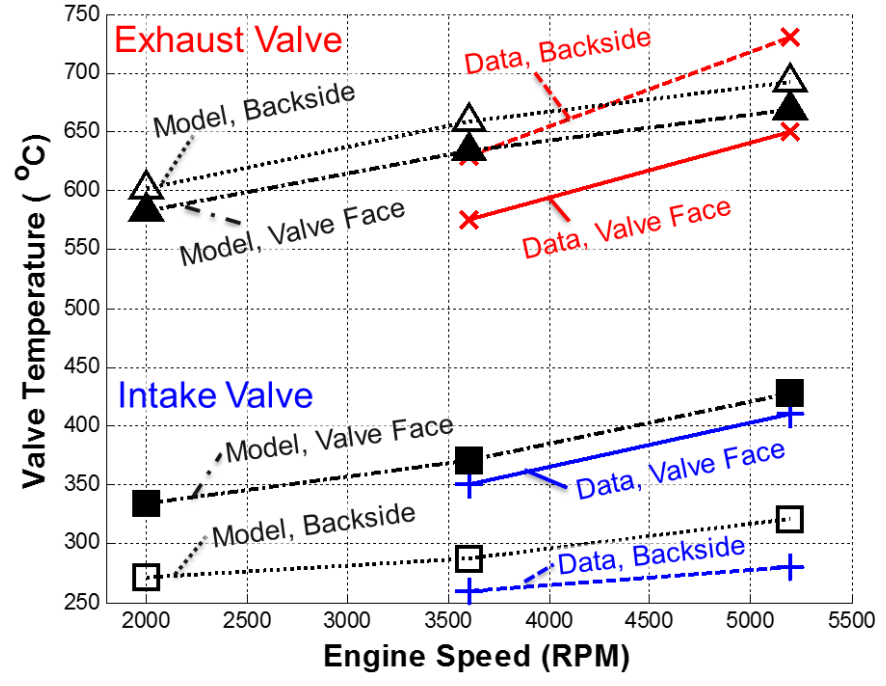

Figure 4: Intake and Exhaust Valve Calibration
Agreement between the experimental data measured by Yang (24) and the results of the thermal model was reasonable, given the assumptions made in generating boundary conditions. Notably, the model predicts the recorded trend that the exhaust valve back temperature is higher than the face temperature, driven by the high temperatures and rates of convection from the exhaust gas flow. Roughly $90 \%$ of the energy flow to the head takes place through the valve seat, as reported by Wisniewski (25), and

the general trends of temperature with speed are captured. The exhaust valve face and back temperatures were much closer to each other in the model because of the geometric simplifications of the valve which confined the valve back heat transfer to the top of the valve head, and removed the radius between the valve head and valve stem. The model overpredicted the intake valve back temperature because fuel vaporization off of the back of the valve for a port-fuel-injected engine was not captured in the model. This factor was neglected as a simplification. However, the difference between intake valve back temperatures of the model and data was equivalent to the energy required to vaporize approximately $20 \%$ of the fuel injected for these conditions.

\section{Results and Analysis}

\section{Temperature Swing Critical Depth}

An understanding of the nature of the temperature swing within the wall is necessary to analyze a highly transient heat transfer environment. The representative thermal "Fourier Number" describes the relationship between diffusion and inertia terms in heat transfer. Physically, it is the ratio of thermal conductivity to heat capacity, and takes into account the cyclic frequency. Assanis et. al. (19) proposed that it can be used to estimate the depth that a temperature wave will propagate within a constant material. The results of the relationship used to calculate a critical depth at which temperature waves have decayed to $1 \%$ of their surface amplitude (critical depth $1 \%$ ) are shown in Figure 5, where a cyclical transient heat flux is applied to the surface at 0 and a constant thermal sink is applied at the backside at a normalized depth of 10 . Despite widely varying thermal properties, the depth ${ }_{1 \%}$ is captured. The portion of the material closer to the surface experiences much greater transient temperature swings throughout the cycle, while material beyond the depth ${ }_{1 \%}$ primarily contributes to the structural thermal environment through steady conduction alone. 

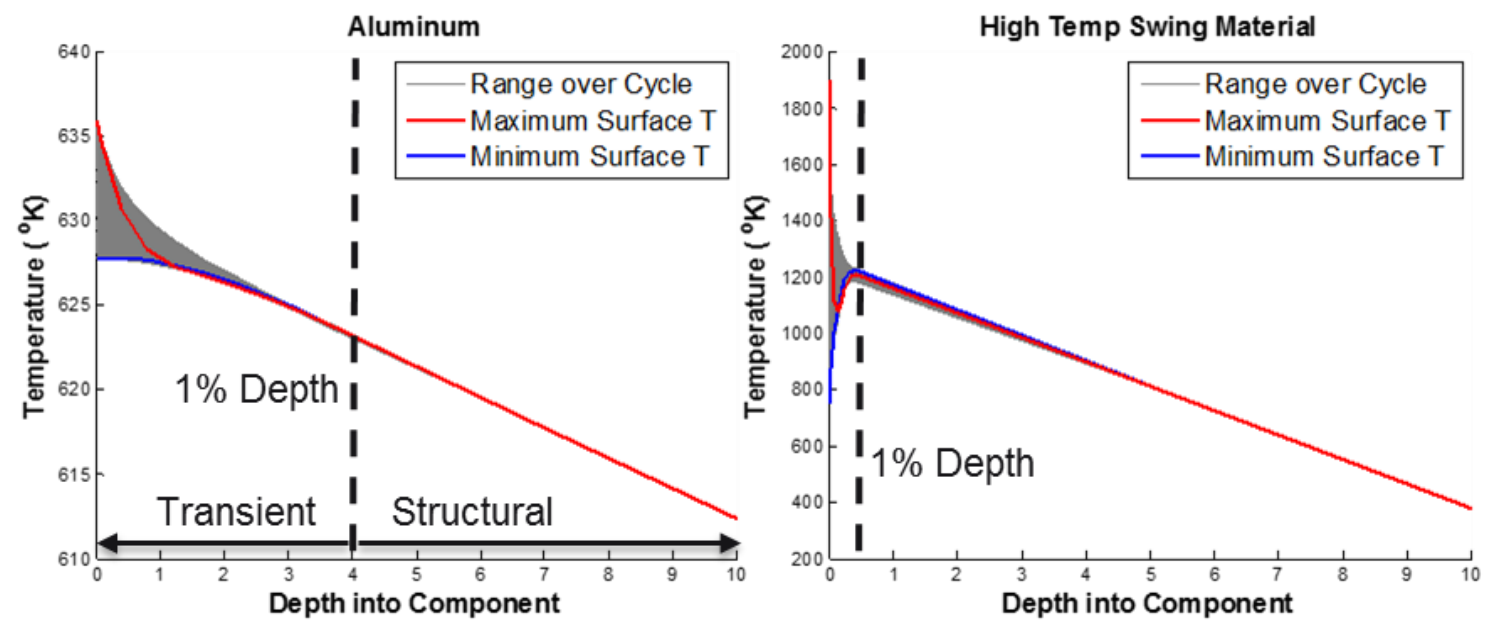

Figure 5: Decay of Temperature Swing with Normalized Depth into a Component

The relationship to calculate the depth ${ }_{1 \%}$ is shown in Equation 2. A constant of 2.0 was added to this equation based on unique modeling results for a variety of materials under different engine conditions.

$$
\operatorname{depth}_{1 \%}=2.0 \times \sqrt{\frac{k}{\rho \times C \times f}}=2.0 \times \sqrt{\frac{60 \times n_{c} \times k}{\rho \times C \times S_{e n g}}}
$$

Equation 2

" $f$ " is the frequency at which the temperature profile repeats, which is calculated from the engine speed " $S_{\text {eng }}$ " in rpm and the firing frequency " $n_{c}$ " in revolutions/cycle. The depth $_{1 \%}$ is very important in the design of parts that include thermal barrier materials with temperature swing properties, and was also used as a basis for optimizing node placement within the TWTS model.

Following from the above, additional structural insulation beyond the depth $1 \%$ serves to primarily increase the total thermal resistance of the component. The equivalent thermal resistance is the combined resistance to heat flow of the coating, the substrate, and the convection coefficient from the backside of the substrate to the temperature sink. This is inversely proportional to heat loss with steady boundary conditions, and therefore represents the total restriction to steady heat flow through a structure. Calculation of the equivalent thermal resistance is shown below in Equations 3 through 5. The total thermal resistance of a coating and substrate composite structure is the sum of the individual terms from conduction and convection of each layer.

$$
\begin{array}{lr}
\boldsymbol{R}_{\text {equiv,Conduction }}=\frac{d}{k} \equiv \frac{\text { thickness }}{\text { thermal conductivity }} & \text { Equation } 3 \\
\boldsymbol{R}_{\text {equiv,Convection }}=\frac{1}{h} \equiv \frac{1}{\text { convection coefficient }} & \text { Equation } 4 \\
\boldsymbol{R}_{\text {equiv,Total }}=\boldsymbol{R}_{\text {Cond,Coating }}+\boldsymbol{R}_{\text {Cond,Substrate }}+\boldsymbol{R}_{\text {Conv,Backside }} & \text { Equation } 5
\end{array}
$$

\section{Fixed Thermodynamic Conditions - Simple Engine Geometry}

Three hypothetical materials were explicitly examined to gain insight into the interplay between material thermal properties and heat transfer in a reciprocating internal combustion engine. Hypothetical material \#3 was chosen to give similar representative properties to solid metals typically used in engine construction, and hypothetical \#2 was chosen to be similar to "state-of-the-art" temperature swing insulation like Toyota's 
SiRPa and moderately porous sprayed zirconia. Hypothetical \#1 carries these trends further to predict desirable properties for a novel, highly porous insulating material. The properties of these materials are plotted in Figure 7. Initially, a layer of Hypothetical material \#1 was applied with variable thickness over a 10mm thick substrate composed of Hypothetical material \#3. It was assumed that the coating and substrate were wellbonded, and thus there was no thermal contact resistance between them. The backside of the substrate was in contact with a $100^{\circ} \mathrm{C}$ thermal sink through a $1400 \mathrm{~W} / \mathrm{m}^{2}-\mathrm{K}$ convection coefficient. A representative high-load gas temperature and heat transfer coefficient were generated by the thermodynamic model, and were kept constant in this study despite changing wall temperatures and total heat loss rates for simplicity and computational speed. It is recognized that as heat losses from the gas to the wall are reduced, the gas temperature will remain hotter, which will increase heat losses later in the cycle. Therefore the results of this study represent an optimistic prediction of the magnitude of the wall temperature swing for these conditions, and the effects of that swing on heat losses.
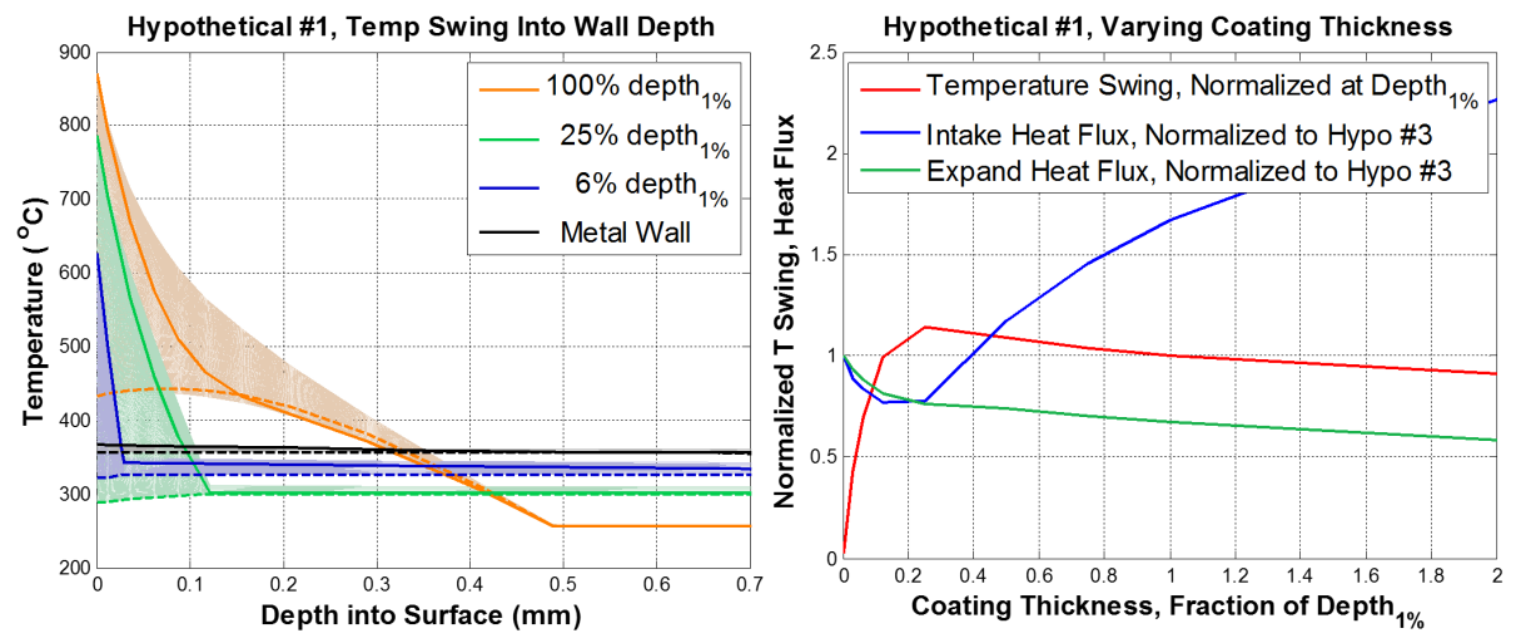

Figure 6: Effects of Coating Thickness on Temperature Swing

The optimum coating depth was found as a function of the depth $1 \%$ for a layer of material \#1 over the metal-like substrate, presented in Figure 6. The plot on the left shows the temperature swing as it travels through the depth of the coating before reaching the coating-substrate interface. The solid lines represent the temperature profile when the surface temperature is at its maximum, while the dashed lines show the profile when the surface is coolest. The shaded area for each color shows the entire range of temperatures experienced at each depth. Heat passes through the coating as a cyclical wave, with a phase delay between the surface peak and the peak at a given depth. This explains why the profile for the coolest surface temperature with the $100 \%$ depth $_{1 \%}$ coating shows a local peak at approximately $0.1 \mathrm{~mm}$; the temperature wave in the coating has only penetrated $0.1 \mathrm{~mm}$ between the previous peak heat flux and the occurrence of minimum surface temperature almost a full cycle later. Material at a depth greater than this point still experiences temperature swing over the course of a cycle but the additional coating thickness beyond this point primarily contributes thermal resistance, increasing the average wall temperature with little effect on the amount of temperature swing. 
The plot on the right in Figure 6 shows the total temperature swing at the surface of the coating as a function of the coating thickness, normalized by the temperature swing at $100 \%$ of the depth $1 \%$. The temperature swing peak is at $25 \%$ of the depth $1 \%(0.125 \mathrm{~mm})$, where the heat wave is essentially anchored at the point where the profiles for minimum and maximum surface temperature cross due to the much higher heat capacity and conductivity of the substrate. Coatings thinner than $25 \%$ are overly constrained by the thermal inertia of the substrate and therefore have rapidly decreasing swing as demonstrated by the $6 \%$ depth $_{1 \%}$ case. Thicker coatings exhibit less swing than the $25 \%$ case because residual thermal oscillation from previous cycle thermal waves deeper in the coating destructively interfere with the current cycle thermal wave, decreasing the surface swing by $15 \%$ for the $100 \%$ depth $_{1 \%}$ example. This is illustrated by the $100 \%$ minimum and maximum temperature lines crossing in the left plot.

The average heat flux during the intake stroke is also shown in the right plot in Figure 6, normalized by the intake heat flux using hypothetical material \#3 (metal wall). As the coating thickness of hypothetical material \#1 increases, the heat flux between the gas and the wall is initially decreased, showing a reduction in intake charge heating from the wall. In the range from 0 to $25 \%$, greater swing is achieved with thicker coatings which allows the minimum surface temperature to drop below the metal-wall temperature, outpacing the effect of increased thermal resistance in raising the cycle-averaged surface temperature. Normalized heat flux during expansion is also shown here, and decreases rapidly as wall temperature swing is established. Beyond $25 \%$ of the depth ${ }_{1 \%}$, added coating thickness primarily increases the thermal resistance without commensurate temperature swing gains, which more slowly decreases the expansion-stroke heat transfer solely by driving up the average surface temperature and slowing the temperature decay after the peak. Both of these effects hurt the intake and compression stroke heat flux, as can be seen by the hotter surface temperatures prior to $0^{\circ}$ and beyond $360^{\circ}$ in the left plot in Figure 7.
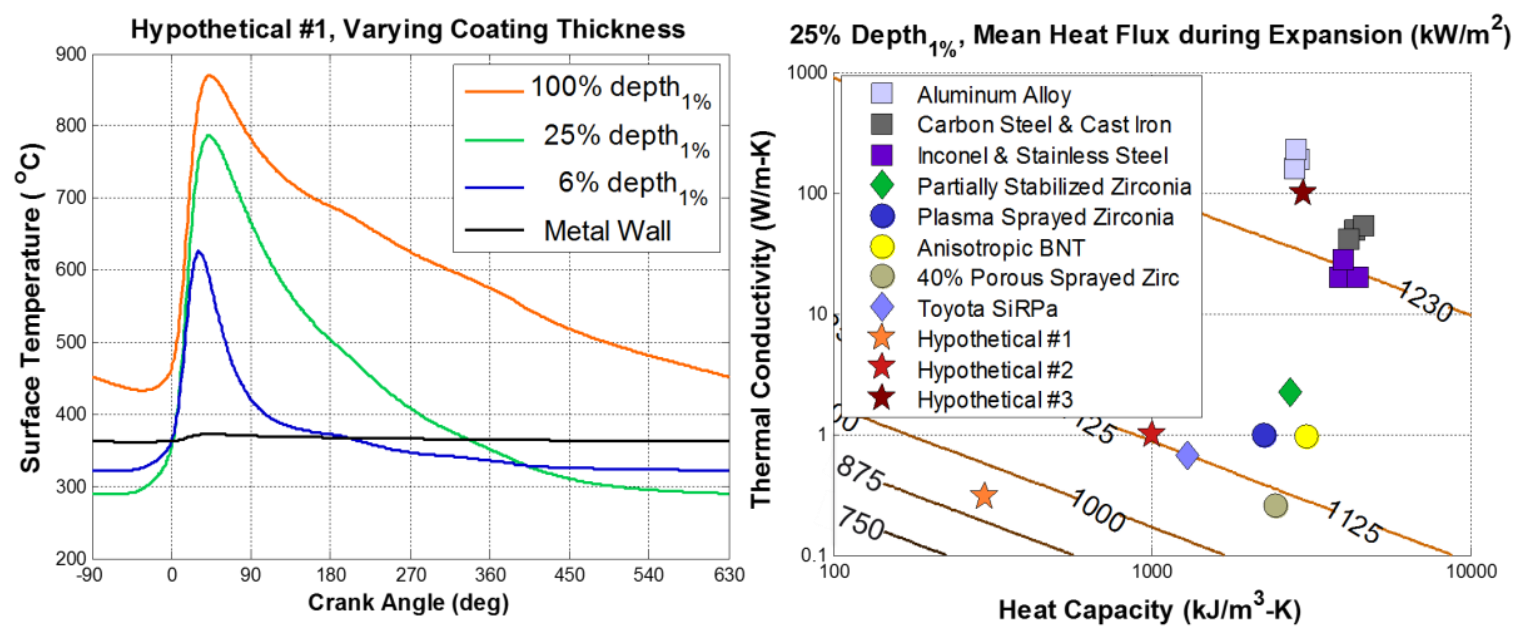

Figure 7: Optimized Coating Thickness and Properties

Thermal conductivity and heat capacity were varied independently over a wide range, with the coating thickness set at $25 \%$ of the depth $1 \%$ as calculated for each combination of properties, shown in the plot on the right in Figure 7. It can be seen that the effects of 
varying material properties on the heat flux are small in the range associated with conventional metal alloys, but that the rate of heat flux reduction increases dramatically as properties move to the lower left of the plot beyond the range of conventional insulating materials. All of the trends discussed with respect to coating depth were confirmed at multiple other material properties combinations as well.

Fundamentally, these results are valid for any operating condition, since the depth that a temperature wave propagates into a material are only dependent on the material properties and the frequency of the cyclical heat flux. However, for a coating with fixed depth designed to work optimally at a certain frequency (engine speed), operation at a different frequency results in a different depth ${ }_{1 \%}$, and thus the fixed coating thickness would represent a different percentage of the depth $1 \%$. The inverse square root of the frequency impacts the depth ${ }_{1 \%}$, so slower operation will decrease the percentage, but not linearly. If a coating is applied at $25 \%$ of its depth $1 \%$ calculated at 2000 RPM, operation at 1000 RPM will make the fixed coating depth equivalent to $18 \%$ of the depth $1 \%$ at this speed, and operation at 6000 RPM would make the fixed coating $43 \%$ of the depth $1 \%$ at this speed. Therefore, at 1000 RPM, the heat loss during the intake stroke is slightly less negative (less intake heating), but the insulation is less effective during the expansion stroke. Conversely, at $6000 \mathrm{rpm}$, heat losses are lower during expansion, and heat transfer from the walls to the gas during the intake stroke is slightly higher than with conventional un-coated walls. This should have the effect of improving the engine's knock tolerance at low speeds while minimally penalizing volumetric efficiency at high loads, all while enabling maximum temperature swing of the coating for reduced heat losses during combustion and expansion.

\section{Variable Thermodynamic Conditions - Simple Engine Geometry}

The same 1-dimensional thermal engine geometry was assumed for this comparison and the "Fixed Thermodynamic Conditions" study above, and the engine was operated at the "High Load" point. All combustion chamber surface temperatures were set to the surface temperature value of the simple 1D solution. Layers of the simple wall used in the various cases is described in Table 2.

Table 2: Thermal Case Geometries

\begin{tabular}{|r|c|c|c|c|}
\hline Case & \#1 & \#2 & \#3 & Baseline \\
\hline Coating Material & Hypo. \#1 & Hypo. \#2 & None & None \\
\hline Coating Thickness & $0.122 \mathrm{~mm}$ & $0.122 \mathrm{~mm}$ & None & None \\
\hline Base Material & Hypo. \#3 & Hypo. \#3 & Hypo. \#3 & Hypo. \#3 \\
\hline Base Thickness & $4.18 \mathrm{~mm}$ & $4.18 \mathrm{~mm}$ & $45.0 \mathrm{~mm}$ & $4.30 \mathrm{~mm}$ \\
\hline
\end{tabular}

Cases \#1 and \#2 represent a coating of hypothetical material \#1 and \#2 respectively over a metal substrate composed of material \#3 with the coating thickness specified as $25 \%$ of the depth $1 \%$ of the coating material. The total thickness of the walls for cases \#1 and \#2 is the same as for the baseline, which is made of only hypothetical material \#3. Case \#3 also consists of only material \#3, but the thickness is increased so that the total thermal resistance of the wall is the same as Case \#1. Therefore, the comparisons presented by 
this analysis are of different materials used as an insulating coating within a constant thickness part (Case \#1, \#2, and Baseline), and the effects of equal thermal resistance with and without appreciable wall temperature swing (Case \#1 and \#3).

The wall surface temperature swing for hypothetical material $\# 1$ is over $700^{\circ} \mathrm{C}$ as shown to the left in Figure 8, which is greater than predicted in the fixed thermodynamic analysis above. The increased level of swing is driven by a peakier heat loss rate in this comparison, due to the different pressure and temperature profiles of the gas. In a steadyheat-transfer scenario, walls of equal thermal resistance would have the same surface temperatures, and the heat transfer rate would be constant between the two cases. Conversely, a cyclical heat source such as the gas in a reciprocating internal combustion engine drives materials with lower thermal inertia to track the gas temperature more closely, decreasing heat transfer over materials with identical thermal resistance but high thermal inertia. Hypothetical material \#1 reduced the peak heat transfer rate by almost 25 $\mathrm{kW}$ in comparison to case \#3 while cutting the heat transferred from the wall back to the gas during the intake and compression process by approximately half. This resulted in a lower average surface temperature for case \#1 than case \#3, despite identical thermal resistances. All three cases reduced the amount of heat transfer when compared to the baseline, but in much different ways.
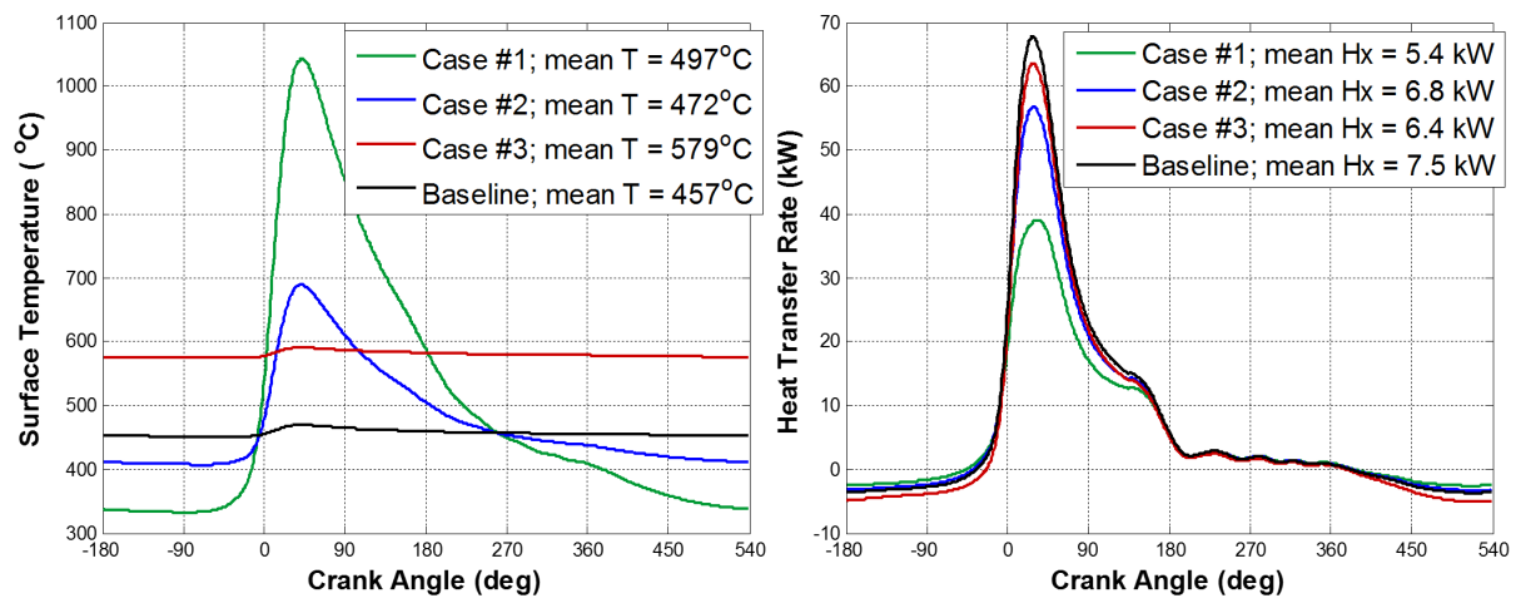

Figure 8: Surface Temperatures and Total Heat Transfer Rates at "High Load" Point

The observed temperature swing and resulting reduction in heat transfer for hypothetical material \#2 are more modest than case \#1 despite its thermal conductivity and heat capacity appearing closer to material \#1 than to material \#3 in Figure 6. Assanis (19) suggested that the expected temperature swing is a function of the thermal conductivity and heat capacity as described in Equation 1. Adjusting this proportional equation such that the surface temperature swing of material \#3 is accurately calculated, material \#1 only achieves $72 \%$ of the theoretically predicted swing, while material \#2 achieves $92 \%$ of the theoretical swing. The difference is because the heat transfer rate is coupled to the surface temperature swing; as the swing gets greater, the difference in temperature between the gas and wall at the peak of the heat transfer rate driving the swing decreases, which mitigates the wall temperature swing increase when compared to theoretical predictions against a constant thermal driver. 
Figure 9 shows the differences from the un-coated baseline in the total heat transfer rate and the combustion chamber gas temperature. The differences were plotted to highlight the effects of each insulation configuration on the heat transfer process throughout the engine cycle. Positive differences indicate that there was more heat transfer from the gas to the walls for the specified case than the baseline, or that the gas in the specified case was hotter, respectively. At this operating point the temperature swing coatings in cases \#1 and \#2 have the desired effect of decreasing heat transfer and thus increasing the gas temperature during the expansion and exhaust strokes while reducing the gas temperature during the intake and compression strokes. Case \#3 also reduced heat transfer during combustion and exhaust, but not to the same extent, and it increased the gas temperature during intake and compression. When the heat transfer rate of the baseline case was negative (heating the gas), cases \#1 and \#2 made it less negative which resulted in less intake air heating while the much hotter wall of case \#3 heated the gas more. Therefore, a positive difference in heat transfer rate is desirable during the intake and compression strokes, and a negative difference is desirable during expansion and exhaust.
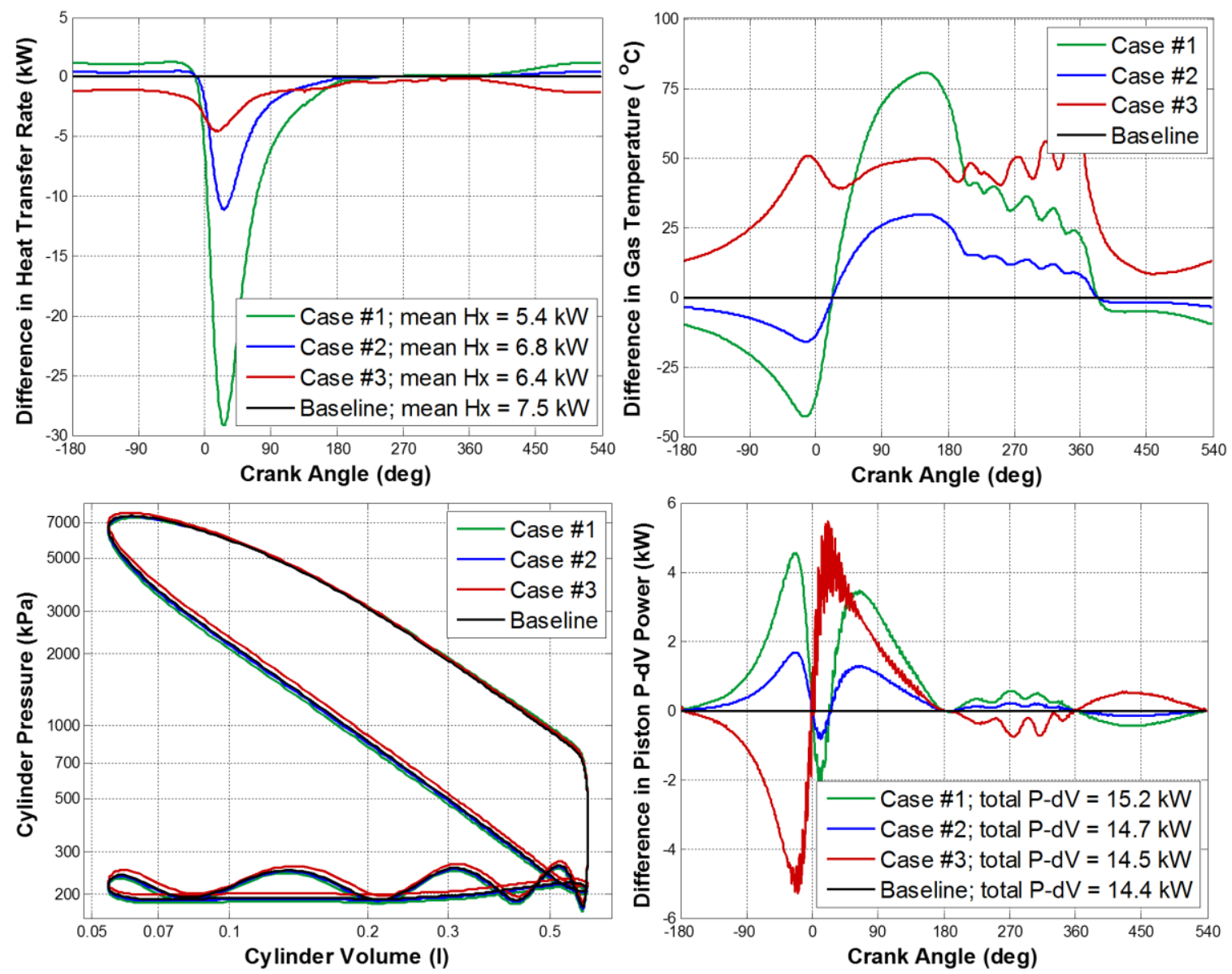

Figure 9: Difference in Heat Transfer Rate, Gas Temperature, Instantaneous Indicated Power, Logarithmic P-V

The temperature swing materials improved the engine's volumetric efficiency (VE) by $3.6 \%$ for case \#1 and by $1.3 \%$ for case \#2, which lowered the intake pressure requirement for a fixed air mass flow and thus kept the pressure lower during compression. Case \#3 suffered a reduction in VE of $4.1 \%$ due to the hotter, less dense air in-cylinder. The 
effects on the gas pressure and instantaneous indicated piston work are shown in Figure 9. The overall shape of the P-V curves are very similar, but cases \#1 and \#2 can be seen at a lower absolute pressure than the baseline for the entire cycle except for the end of expansion, while case \#3 is at consistently higher pressure than the baseline. Therefore the power required for compression for cases \#1 and \#2 was decreased, appearing as positive due to the difference. Conversely, case \#3 required more work for compression. The greater pressure during expansion for all three cases is apparent as a positive difference in power versus the baseline. Expansion gains are barely sufficient to offset the compression losses for case \#3, but are in addition to compression gains for cases \#1 and \#2. The differences during the gas exchange process are negligible because the exhaust pressure was pegged with a fixed difference to the intake pressure. Notably, if the intake pressure was fixed instead of controlled to hold mass flow constant, then the differences would be seen almost exclusively in the expansion stroke but the results would be muddied due to the leaner AFR or different fuel energy which would affect the gas temperature more significantly.

Approximately $1 / 3^{\text {rd }}$ of the energy that is prevented from leaving the gas during the expansion stroke for cases \#1 and \#2 was recovered by the piston, in contrast to less than $1 / 6^{\text {th }}$ for case \#3. A reduction in heat transfer early into the expansion stroke allows for the most potential work extraction since the piston still has the majority of the expansion to perform, allowing the greatest positive change in volume over which to increase piston work as discussed by Morel with the concept of "Pumped Heat" (10). The rest of the energy prevented from leaving the gas remained in the exhaust, for an increase of $39.3^{\circ} \mathrm{C}$ for case \#1, $14.4^{\circ} \mathrm{C}$ for case \#2, and $28.6^{\circ} \mathrm{C}$ for case \#3. Overall the NSFC has improved by $4.9 \%$ for a coating of material \#1, by $1.9 \%$ for a coating of material \#2, and by $0.5 \%$ for case \#3. It is clear that the greater the temperature swing potential of the material, the greater the conversion of gains from insulation during expansion to indicated work; otherwise most of the energy is left in the exhaust stream. Even case \#2, which has approximately $1 / 3$ of the thermal resistance of case \#3 outperforms it in net indicated work despite having higher average heat losses.

\section{Variable Thermodynamic Conditions - Realistic Engine Geometry}

The complete engine thermal model including all components was employed for this study, using the geometries and backside heat transfer coefficients calibrated to experimental data as detailed previously unless otherwise specified. The piston top surface and intake and exhaust valve faces were specified using the same materials and thicknesses as in Table 2, while the piston skirt and valve stems were unchanged from the model formulation as it was calibrated. Case \#3 was not simulated, as the extreme component thicknesses were not realistic. Only the piston and valve faces were insulated since together they comprise almost $70 \%$ of the combustion chamber surface area at TDC; other surfaces were specified as material \#3 for all cases. Initially, the "High Load" operating condition is analyzed to describe the effects due to engine geometry. Finally, the results at all three described operating conditions are examined. 

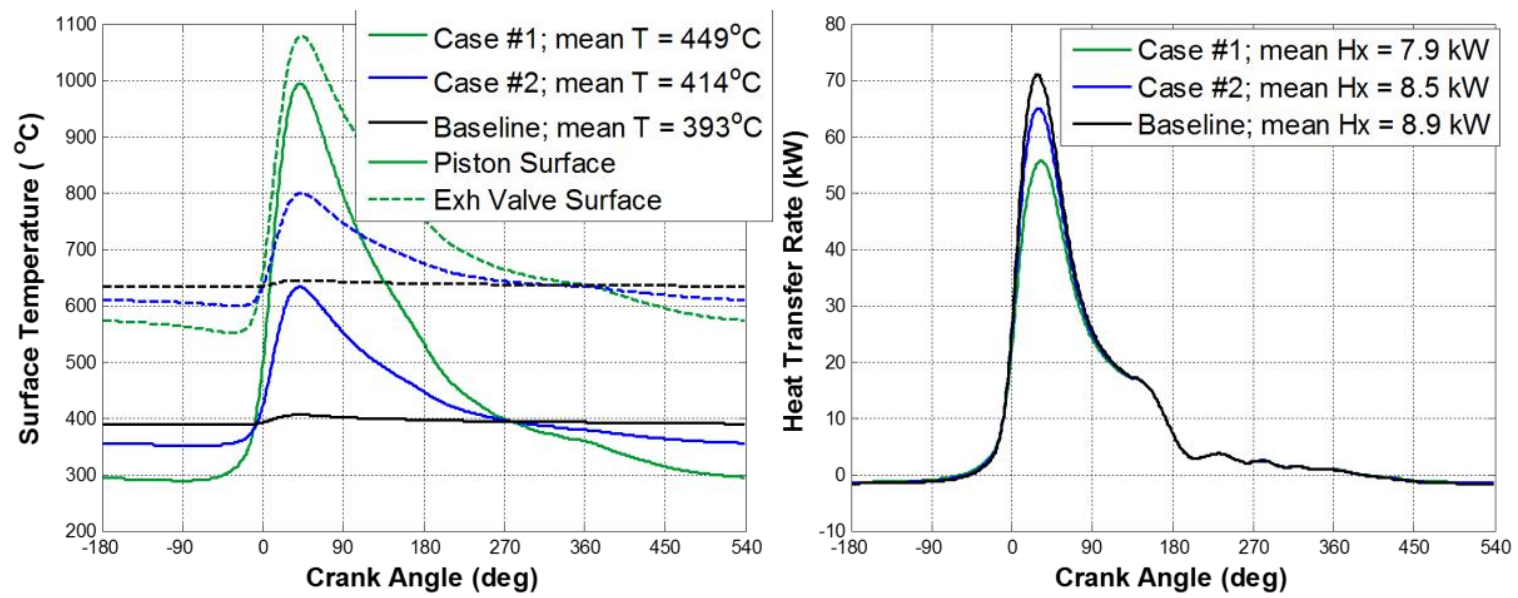

Figure 10: Surface Temperatures and Total Heat Transfer Rates for Complete Engine Geometry, High Load Point

The surface temperatures for the piston and the exhaust valve face are shown to the left in Figure 10. The exhaust valve surface had less temperature swing than the piston surface for all material cases because flow of the exhaust gas over the backside of the valve is presenting a competing cyclical heat addition to the component out-of-phase with the heat flux from the combustion chamber. The temperature wave from the valve backside travels through and destructively interferes with the surface temperature swing, lessening the magnitude of the surface swing. The intake valve temperature profiles were largely the same as the piston profiles since heat transfer between the valves and the intake flow did not represent as much of a departure from the in-cylinder heat transfer conditions, but $40^{\circ} \mathrm{C}$ lower as the intake air temperature sink was much cooler than the oil. Additionally, the average piston temperatures (shown in the legend) are lower than the wall temperature from the previous section despite having the same back-side heat transfer coefficient to the oil because a heat transfer path to the bore has been added as part of the realistic engine geometry. The bore and head have a much higher heat transfer coefficient to the coolant befitting forced fluid-wall convection which reduced their temperatures relative to the piston, resulting in a higher cycle-averaged heat transfer rate.

Overall heat transfer rates from the gas to the coolant were not as different between material cases as in previous sections because only a portion of the combustion chamber surface was insulated. Near TDC when heat transfer was greatest, the coated surfaces represented almost $70 \%$ of the exposed surface area, and the wall temperature swing contributed to reducing the peak rate. Other times in the cycle had more bore area exposed and the coated surface temperature was similar to the un-coated temperature, both of which reduce the difference in heat transfer rate to the baseline. Roughly 1/3 of the heat kept in the gas during expansion is still recovered by the piston, but the total magnitude of these energies is approximately half of the previous comparison where all the walls were coated. 

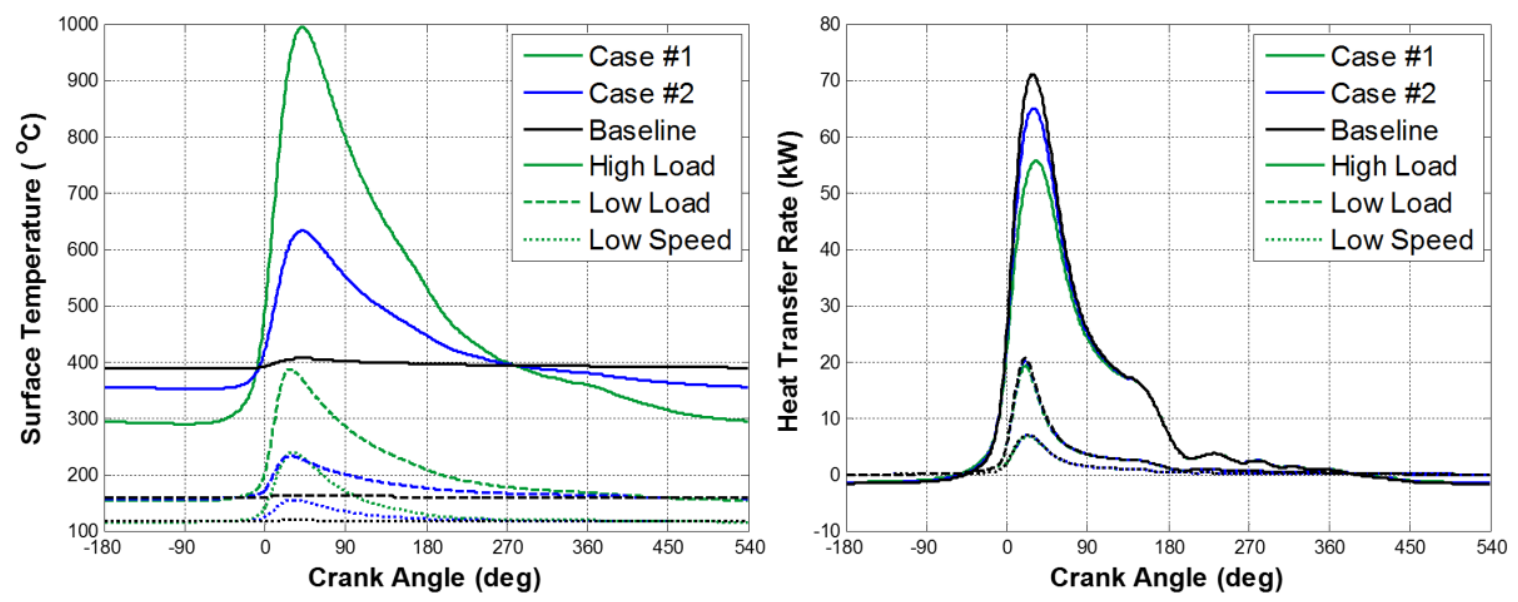

Figure 11: Piston Surface Temperatures and Total Heat Transfer Rates for All Points

The differences between material coatings is most pronounced at the high load point, shown for the piston surface as solid lines in Figure 11. Wall temperature swing is still noted at lower speeds and loads, but it is reduced since the fuel energy and thus heat transfer rate driving the swing is reduced. The smaller wall temperature swing is reflected in the difference in peak heat transfer rate between the three materials at lower loads and speeds. At low speed, expansion heat loss is reduced by more than an order of magnitude, due to the lower fuel energy, flows, pressure and temperature. Heat transfer for the low load and speed cases is also essentially zero outside of the expansion stroke. This basically eliminates the differences in temperature seen during the intake and compression stroke since the coating has sufficient time to cool through conduction to the underlying substrate and reach similar temperatures to an un-coated component without heat transfer to the gas. At these speeds and loads there should be no impact on volumetric efficiency expected; however this is not a bad thing since these points are throttled and any increase in VE would need to be accompanied by greater throttling and higher pumping losses.
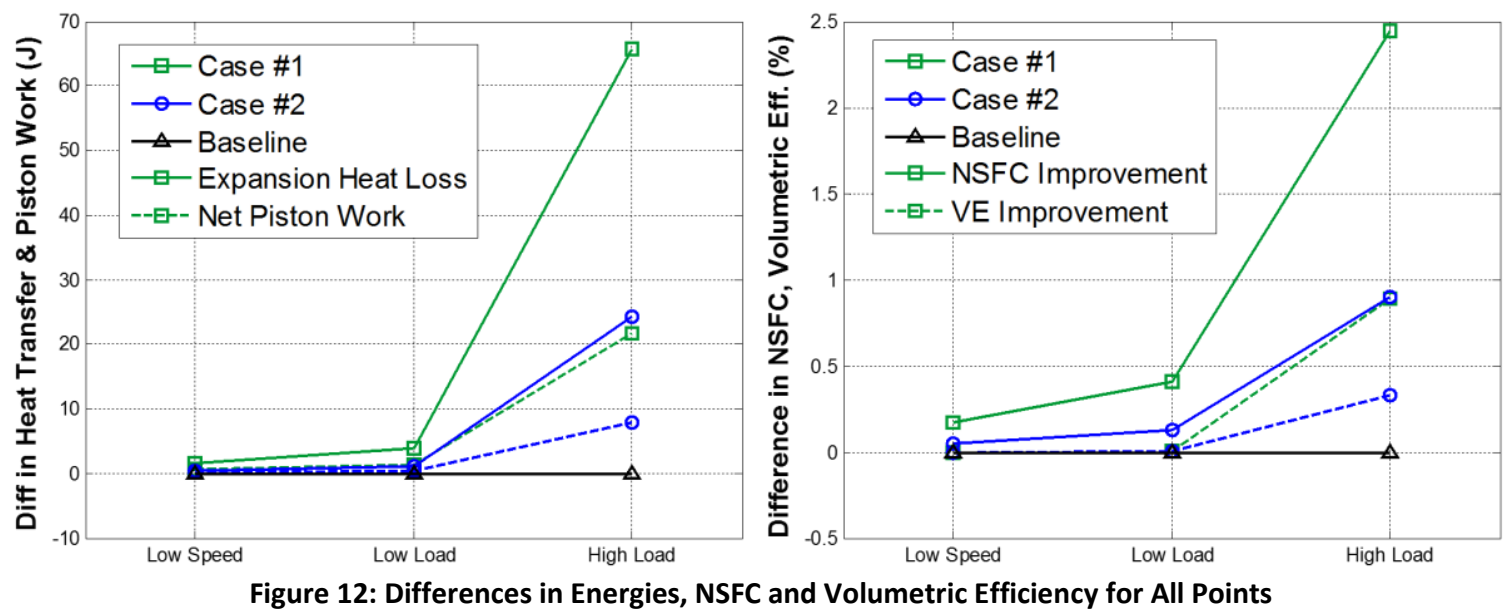

As observed before, the high load operating point demonstrated the largest difference between the coating materials. The low load and low speed points did not allow the coatings to prevent much additional energy from leaving the gas, and therefore the differences in piston work and thus NSFC are very small for these points. Consistently, 
almost $1 / 3$ of the additional energy prevented from being lost to the walls during expansion was converted into net indicated work by the piston when using temperatureswing materials for all points, as analyzed previously. Volumetric efficiency was unchanged at low speeds and loads, and was actually improved at high load by these coatings, demonstrating that temperature-swing materials can have both a breathing and an efficiency benefit.

\section{Summary and Conclusions}

Thermal barrier materials that enable wall temperature swing show the potential to improve the performance of reciprocating internal combustion engines without negatively impacting engine breathing or knock tendencies.

- Low heat capacity and low thermal conductivity both promote surface temperature swing in combustion chamber wall materials.

- Coating thickness of a temperature-swing material has a large influence on the amount of temperature swing, the total insulation capability, and the rate of temperature decay during expansion and exhaust, which all will affect engine performance.

- Wall temperature swing in response to the engine's instantaneous heat flux can reduce heat transfer more effectively than conventional insulation without the traditional negative impacts on volumetric efficiency or incylinder thermal environment.

- Benefits from wall temperature swing derive from a reduction in compression work required as much as they do from an increase in expansion work recovered.

- Approximately $1 / 3$ of the energy prevented from leaving the gas during the expansion stroke can be recovered by the piston using wall temperature swing coatings of proper thicknesses, while conventional bulk insulation would force the engine to expend much of that recovered energy on additional compression.

- Greatest benefits are found at high load where the heat transfer rates that drive wall temperature swing are highest.

- Large amounts of wall temperature swing can substantially improve the efficiency of reciprocating internal combustion engines, but there are significant challenges in achieving the hypothetical thermal properties proposed and durability required to withstand the rapid thermal cycling that high levels of temperature swing would impose. Inclusion of high levels of porosity offer an interesting avenue for achieving these goals while improving the material's bulk ductility to reduce thermal stresses. 


\section{References}

1. Kosaka, H.,Wakisaka, Y., Nomura, Y., Hotta, Y., Koike, M., Nakakita, K., Kawaguchi, A. Concept of "Temperature Swing Heat Insulation" in Combustion Chamber Walls, and Appropriate Thermo-Physical Properties for Heat Insulation Coat. Warrendale, PA : SAE 2013-01-0274, 2013.

2. Kogo, T., Hamamura, Y., Nakatani, K., Toda, T., Kawaguchi, A., Shoji, A. High Efficiency Diesel Engine with Low Heat Loss Combustion Concept - Toyota's Inline 4Cylinder 2.8-Liter ESTEC 1GD-FTV Engine. Warrendale, PA : SAE 2016-01-0658, 2016.

3. Wakisaka, Y., Inayoshi, M., Fukui, K., Kosaka, H., Hotta, Y., Kawaguchi, A., Takada, N. Reduction of Heat Loss and Improvement of Thermal Efficiency by Application of "Temperature Swing" Insulation to Direct-Injection Diesel Engines. Warrendale, PA : SAE 2016-01-0661, 2016.

4. Performance and Emission Characteristics of a low heat rejection spark ignited engine fuelled with E20. Kumar, C., Nagarajan, G. s.1. : Joural of Mechanical Science and Technology, 2012, Vols. 26 (4), 1241-1250.

5. The Impact of a Magnesium Zirconate Thermal Barrier Coating on Homogeneous Charge Compression Ignition Operational Variability and the Formation of Combustion Chamber Deposits. Hoffman, M., Lawler, B., Guralp, O., Najt, P., Filipi, Z. s.l. : International Journal of Engine Research, 2015, Vols. 16 (8), 968-981.

6. Kamo, R., Bryzik, W. Adiabatic Turbocompound Engine Performance Prediction. Warrendale, PA : SAE 780068, 1978.

7. Woschni, G., Spindler, W., Kolesa, K. Heat Insulation of Combustion Chamber Walls - A Measure to Decrease the Fuel Consumption of IC Engines? Warrendale, PA : SAE 870339, 1987.

8. Havstad, P., Garwin, I., Wade, W. A Ceramic Insert Uncooled Diesel Engine. Warrendale, PA : SAE 860447, 1986.

9. Timoney, S., Flynn, G. A Low Friction, Unlubricated SiC Diesel Engine.

Warrendale, PA : SAE 830313, 1983.

10. Morel, T., Fort, E.F., Blumberg, P.N. Effect of Insulation Strategy and Design

Parameters on Diesel Engine Heat Rejection and Performance. Warrendale, PA : SAE 850506, 1985.

11. Furuhama, S., Enomoto, Y.,. Heat Transfer into Ceramic Combustion Wall of Internal Combustion Engines. Warrendale, PA : SAE 870153, 1987.

12. Sudhakar, V. Performance Analysis of Adiabatic Engine. Warrendale, PA : SAE 840431, 1984.

13. Bryzik, W. and Kamo, R. TACOM/Cummins Adiabatic Engine Program. Warrendale, PA : SAE 830314, 1983.

14. Wallace, F., Way, R., Vollmert, H. Effect of Partial Suppression of Heat Loss to Coolant on the High Output Diesel Engine Cycle. Warrendale, PA : SAE 790823, 1979.

15. Way, R., Wallace, F. Results of Matching Calculations for Turbocharged and Compound Engines with Reduced Heat Loss. Warrendale, PA : SAE 790824, 1979. 16. Wallace, F., Kao, T., Alexander, W., Cole, A., Tarabad, M. Thermal Barrier Pistons and Their Effect on the Performance of Compound Diesel Engine Cycles. Warrendale, PA : SAE 830312, 1983. 
17. Morel, T., Keribar, R. and Blumberg, P. Cyclical Thermal Phenomena in Engine Combustion Chamber Surfaces. Warrendale, PA : SAE 850360, 1985.

18. Miyairi, Y. Computer Simulation of an LHR DI Diesel Engine. Warrendale, PA : SAE 880187, 1988.

19. Assanis, D., Badillo, E. Transient Heat Conduction in Low-Heat-Rejection Engine Combustion Chambers. Warrendale, PA : SAE 870156, 1987.

20. Kamo, R., Assanis, D., Bryzik, W. Thin Thermal Barrier Coatings for Engines. Warrendale, PA : SAE 890143, 1989.

21. Woschni, G. A Universally Applicable Equation for the Instantaneous Heat Transfer Coefficient in the Internal Combustion Engine. s.l. : SAE Transactions, Vol. 76, 3065, 1967.

22. Guralp, O., Najt, P., Filipi, Z. Method for Determining Instantaneous Temperature at the Surface of Combustion Chamber Deposits in an HCCI Engine. Vancouver, BC, Canada : ASME ICEF2012-92188, 2012.

23. Chang, J., Guralp, O., Filipi, Z., Assanis, D., Kuo, T., Najt, P., Rask, R. New Heat Transfer Correlation for an HCCI Engine Derived from Measurements of Instantaneous Surface Heat Flux. Warrendale, PA : SAE 2004-01-2996, 2004.

24. Yang, L., Hamada, A., Ohtsubo, K. Engine Valve Temperature Simulation System. Warrendale, PA : SAE 2000-01-0564, 2000.

25. Wisniewski, T. Experimental Study of Heat Transfer on Exhaust Valves of 4 C90

Diesel Engine. Warrendale, PA : SAE 981040, 1998.

26. Assanis, D., Badillo, E. Evaluation of Alternative Thermocouple Designs for

Transient Heat Transfer Measurements in Metal and Ceramic Engines. Warrendale, PA : SAE 890571, 1989. 